\title{
Employing Touristic Advertisement Treatments to Enrich the Visual Identity: A Study on Textile Design for Egyptian Coastal Hotels
}

\author{
Shimaa Salah Sadek Sedek ${ }^{1 *}$ and Nashwa Moustafa Nagy $^{2}$ \\ ${ }^{1}$ Department of Advertising, Benha University, Egypt \\ ${ }^{2}$ Spinning, Department of Weaving and Knitting, Benha University, Egypt \\ Submission: July 02, 2019; Published: July 25, 2019 \\ *Corresponding author: Shimaa Salah Sadek Sedek, Advertising Department, Benha University, Egypt
}

\begin{abstract}
Tourism is one of the top priorities of the country as a source of national income, Therefore, the State seeks to promote the tourism sector and its infrastructure. This study assumed that the use of graphics treatments for tourism advertising through the textile furnishing of hotels in coastal cities enriches their visual identity. Also, the synchronized presentation of tourism Ads along with specifically designed textile furnishings can play an active role in confirming the hotel distinctive identity. This experimental study, which involved 150 coastal hotel guests, measured the effect of unified graphic treatments of tourism advertising of coastal hotels in addition to specifically designed textile furnishings and the impact of their synchronization on the guest perception of the visual individuality of the hotel. The study concluded that recruitment of graphic treatments of tourism advertising in the textile furnishings of the coastal hotels enhances the hotel's visual distinctiveness. In addition, the synchronized presentation increased the credibility of the hotel and augmented its characteristic visual identity.
\end{abstract}

Keywords: Graphical treatments; Touristic advertisements; Textile furnishing; Coastal hotels; Visual identity

\section{Introduction}

The political situation that country has faced in the last previous years which accordingly has an impact on tourism sector in whole Egypt generally but especially Cairo and Sinai. As tourists started to switch their directions on Egypt from capital to visiting the Coastal cities thus it becomes recently one of the most important factor on developing and financing the tourism sector because the low number of population, More comfortable and secure to tourists. The increasing on the tourists' number visiting these coastal cities refers to the importance of developing these tourism sectors, where the tourist enjoys many of the coastal characteristics. Hence, we find the importance of highlighting distinctive visual identity of the coastal hotels as the most important factor of comfort and pleasure for tourist during his visit and it can enrich his sense of Egyptian visual tourism identity and the possibility of enjoying it, also it reflects the mental image about his visit to Egypt. The study suggests that the integration of advertising studies and the textile sector of coastal hotels and their accessories to form a distinctive visual identity has become a necessity for these hotels, where the use of graphic treatments for tourism advertising in the textile furnishings of coastal hotels enriches their visual identity to leave a civilized impression in the minds of tourists. In addition, the synchronized presentation of this tourism advertising with those textile furnishings has an active role in confirming the identity of the coastal hotels, which is one of the mental stimuli, which have an effective role in influencing tourists' behaviour, thus advancing the development of tourism, increase tourism income and national economy successively.

This idea has not been investigated previously. This gap in the literature is surprising. Not only because of the efficacy of the advertising using textile designs in creating visual and graphical individual identities for hotel corporations, but also due to its ability to attract tourists to these coastal cities in Egypt for their effectiveness in adding a deportation. Our research starts filling this gap. Specifically, we expect that the ability of graphic treatments for tourism advertisements to create visual images, as the processes of reduction, addition, editing, distortion, integration, complex compositions, abstraction, experimentation, shapes interconnections and elements analysis have an active role in achieving the thrill, attraction 
and dazzling for designs, and provide creative standards for the elements of a successful mental images for the design which will lead to the excellence and remembrance for these visual elements and it will put the tourist on a certain atmosphere on the coastal hotel, enjoy the visit from the beginning and then to consolidate this visit to the historical tourism places to leave a strong impression of the civilization of the country and thus the desire of the tourist to repeat the visit. We examine this main proposal through an experimental study based on the use of unified graphic treatments in both the tourism advertising of the coastal hotel and the designs of its textile furnishings to emphasize its distinctive visual identity derived from its tourism and civilization nature. In addition, the study of the synchronized presentation of this tourism advertising with the textile designs of the coastal hotel and its role of this synchronization to enrich the hotel's coastal identity.

Coastal tourism is depending on the pursue of different civilization of the different eras of Egypt which caused the cultural integration between civilization and tourism. Which have also a great impact on attracting tourists and strengthening this civilization and tourism on hotels have a great impact on national security, In addition to the strategic location of coastal cities and its beaches, the treasures of coral reefs and the diversity of fish these all factors that can be used visually to enrich the visual identity of hotels and resorts in different cities such as Sharm el-Sheikh, Dahab, Nuweiba, Alexandria, El Gouna, Hurghada, Ain Sokhna. According to the importance of hotels as one of the requirements of tourism and the basis of tourism structure, the rate of increase of hotels from 1998 to 2006 is relatively high, where it rose from 829 hotels to 1332 villages, bringing the rate of increase to $53 \%$. Accordingly, the capacity rate is gradually increasing to 10 times than the average of housing capacity. As 2007 witnessed the establishment of 160 new hotels and the increase in the number of tourism days to 12\%. [1], especially the success of Egypt in 2017 as the best destination for travel and increasing rates of the existence of coastal hotels until 2018, which indicates the need to give high attention to the hotel industry as it is one of the most important factors for the success of tourism.

Wherefore, this study seeks to embody the distinctive visual identity of coastal hotels using the unified graphic treatments derived from the rich and visually stunning coastal heritage in both the hotel's tourism advertising and its textile furnishings and accessories. In addition to the synchronization of the presentation and study of the impact of this synchronization on the creation and richness of the hotel's visual identity, which works to connect the visual elements of the hotel with its objectives and strategy to promote coastal tourism in Egypt and support the national economy. Last, the result of our study showed strong approval for the relatively high participants. The effective recruitment of graphic treatments for tourism advertising in the textile furnishings of the hotels of the coastal cities enriches the hotel's visual identity and illustrates a distinctive visual entity that represents the determinants and characteristics of this distinctive identity from its competitors. In addition, the synchronized presentation of this tourism advertising with those textile furnishings gave rise to the credibility of the hotel service and its images have a distinctive visual identity resulting from the unification of the formal elements. The results indicated that a positive mental image was established on the coastal hotel.

\section{Theoretical Background}

The world tourism organization agreed on defining tourism as traveling activities out of the tourist normal environment for a period of not more than one year, respectively, for leisure, work or for various other purposes. Also, Weaver and Lawton (2003) defined it as a number of phenomena and relationships arising from interaction between tourists, the tourism industry, host governments, host communities, governments, universities, community colleges and non-governmental organizations in the process of attracting, transporting, hosting and managing tourists and other visitors [2]. The tourism industry is one of the most important means of global communication between countries and peoples. It is the gate from which people learn about different cultures and different societies abroad. Tourism also is one of the most important international industries. Thus, marketing of tourism identity has a central role in expanding this industry. As tourism is considered as a multinational field that has global importance, It is one of the most profitable industries, which in turn causes great economic growth (financial growth), private business, and provide human resources to economy, In addition to the popularity added by the visual identity of tourism to the image of the country globally, tourism is an integral part of the state infrastructure [3].

\section{Tourism Attraction Essence}

The process of attraction is considered as an essence for tourism promotion process and designer concentration on inspiring the prospected tourists with the special visual identity of the coastal cities is one of the most important factors for the conventional promotion process. Tourism attraction is defined as it is the permanent source that controls the income generated by the tourism sector (entrance fees, activities, visits, donations, buying and selling movements, etc.) which designed to entertain tourists primarily. [4] Also (Mayo and Jarvis 1981) defined it as the importance of the individual benefits and the perceived ability of the state as a tourist destination to provide these individual benefits [5]. The attraction of tourism is one of the aspects of current tourism investment due to its role on developing tourism demand also for being an effective informing tool to tourists about service or tourism product, and according to the increase on the international competition to promote tourism to the other countries so the development on this sector is globally increasing as well as the importance of tourism attraction to the Egyptian coastal places. Tourism is often evaluated by tourists' feedback about the country's ability to meet their needs and desires. Previous studies have shown 
that the study of tourist attractions is necessary to understand the elements that encourage tourists to visit. [6] have found that whenever a country is able to meet the tourist needs the greater the tourist attractions and thus become a strong competitor to other tourism alternatives.

[5] suggest that tourism attractions in the country are being enhanced by the importance of the country's tourist attractions, infrastructure, tourism services and products, and the means of living and comfort, as well as the people who provide these services [5]. Which shows the importance of giving attention to the coastal hotels sector as it represents an important source of tourism services, which in turn reflect an important image to tourist about the Egyptian tourism sector, and thus constitute an effective element in the Egyptian tourist attractions.

\section{Tourism Types on Egypt}

There are Several types of Tourism; They differ according to need as follows

\section{Recreational Tourism}

There are many recreational places in Egypt; it has many beaches and its coral reefs and beautiful nature, also the desert places that featuring Sharm el-Sheikh area and other amazing tourist trips, moreover the Red Sea cities and the beautiful mountains, which offer tourists the opportunity to entertain themselves, enjoy nature and recreation [1].

\section{Cultural Tourism}

Egypt represents a source of diversity of civilizations such as Pharaonic, Coptic, Roman, Greek and other civilizations, which are a rich source of heritage and history. This type of tourism provides historical, cultural and heritage knowledge of the various eras to world. As it reflects to tourists the mental image of different ages and the development of the Egyptian human through the ages, reflecting the multiple cultures of different human civilizations and thus it is considered as a platform for cultural tourism.

\section{Medical Tourism}

Egypt is characterized by many places of medical tourism such as Pharaoh's baths, oases and other areas that provide unique therapeutic services and unique in the world, beside that this type of tourism is supporting the other types of tourism in Egypt.

\section{Religious Tourism}

Egypt is characterized by its cultural and religious mix in tourism according to its religious significance, which has assimilated Judaism, Christianity and Islam, such as ancient mosques, luxurious churches, temples and historic monasteries.

\section{Conference \& Exhibition Tourism}

It is one of the modern forms of tourism in the world as it is founded in recent years in accordance with the development of the global economy and political among various countries in accordance with the invitation of countries to attend various conferences to expand its tourism demand base, along with the influx of tourists to attend conferences due to the global development, industrial, technical and growth of human civilization.

\section{Tourism Promotion}

Tourism promotion is defined as a set of marketing efforts to provide as many tourists as possible with the benefits of a tourist product and to convince them that this product will satisfy a genuine need to convince them to make a purchase decision and continue to use this product or service in the future. Tourism promotion is also defined as an attempt to encourage tourists to travel by using the publication of important tourism information about possibilities to visit and the features of country tourism, it is considered as one of the most effective elements of tourism marketing on promoting tourism product or service [7]. As tourism promotion is an urgent need for increasing tourism rates and accordingly increasing Egypt's tourism income beside developing tourism and investment income in coastal cities, and the increase of competitiveness between hotels and coastal resorts to attract the largest number of tourists expected these all are an urgent factor for the development of resorts and tourism services And thus the embodiment of tourism identity became necessary to prepare the expected tourist psychologically and mentally and to leave an effective psychological impact on his visit. As the tourism promotion for visual identity of coastal cities is considered as a state of mind with special characteristics which influence the prospected tourist with its charm.

The designer may use all tourism aspects in Egypt as a means of intellectual and visual support to form the distinctive visual identity of these coastal hotels to increase cultural awareness of the distinctive tourism considerations of these hotels and coastal resorts, as it represents one of the most important comfort and accommodation for tourist during his visit. Thus, this sector has an effective impact on the national economy. Beside the importance of tourism promotion, it is necessary to focus on the requirements of tourism services, amenities and living conditions, especially hotels and resorts, Hence, the role of graphics treatments for tourism advertising is to enrich the visual identity on developing the coastal hotel sector also its role in establishing an effective mental image in the minds of potential tourists. Referred that there are three promotion phases able to evoke tourist behaviour during his tourism decision as follows

a. Media Promotion: Which is the most effective stage before taking the tourism decision, it aims to prepare the tourist to understand and grab his attention to the information.

b. Conventional promotion: It works well during tourism decision-making phase and it is considered as the stage of settling behaviour and intention to purchase the product or tourism service. 
c. Commemorative Promotion: This phase is mainly starting after the completion of the visit and the use of tourism services and products. Therefore, the delivery of reminders has an effective impact and good impression to the visit. Thus, tourism promotion plays an active role on modifying tourism behaviour by ensuring that the tourist visit will be repeated instead of changing the tourism destination to another country [3].

The tourism advertising occupies the most important place in the promotion for tourism campaigns because it has an effective ability to create distinctive visual identities of the Egyptian tourism as [8] referred on her study on the evaluation of the mental image of Egypt in tourism posters and its ability to support tourism, she pointed out that tourism posters have an effective ability to provide mental images that positively affect the minds of the public and that the mental images about Egypt abroad are in urgent need to be improved. Therefore, we find that the tourism advertising is the cornerstone of the tourism promotion process. As It is possible to clarify intangible tourism services and products in visual and mental images to illustrate the psychological and emotional importance to tourist, which in turn enhancing the competitiveness of Egypt as an interesting tourism destination. According to the state's interest in the cultural identity of Egypt, which appeared clearly during the 2018 Youth Conference, this research is a pillar to support the tourism advertising on creating the distinctive visual identity of the tourism sector and hotel to support Egyptian tourism and stimulate positive behaviour towards the identity of the state.

\section{Tourism Advertising and Its Advantages}

The tourism advertising is the most important forms of tourism promotion because it has an impact on tourism demand, growth rates, sales rates, foreign exchange earnings and accordingly the national economy, as it seeks for visiting the tourism destination and enjoying it instead of tourism convoys that send our heritage abroad. Which would cause dangers and harms to the economy of the state? So the focus on inviting tourists to visit and informing them about the benefits of tourism visit is a necessity, so the efforts of the coordinators of the tourism agencies should be combined with the efforts of the tourism authorities to master the broadcasting of a desired visual identity of the heritage and tourism in Egypt for its great role on convincing and affecting the mental state that the tourist will have during the adventure of visiting Egypt. Based on what we have mentioned, It is clear to us that the impact of tourism advertising is not limited to printed advertising or advertising of the Internet or other traditional means of advertising, but it extends to impose the visual identity of tourism entities, hotels and resorts, where the consistency of promotional advertising campaigns with tourism entities and mental image provides an integrated picture to the successful tourism promotion. Therefore, the most important thing for tourist accommodating and his comfort during the trip (hotel or tourist resort) as the determinants that reflect the visual identity of tourism, which also a new competing factor between different hotels and resorts.

There is no doubt that the good tourism service or product needs an effective promotion strategy. Since advertising is distinguished from other elements of marketing, because it has the ability to spread locally and globally, leaving its direct impact on the marketing of tourism industries clearly in different local and international markets, so the success of a specific tourism area based on its way of marketing and reaching tourists. The tourism advertising is part of the marketing for services as it helps to a large extent on the influx of tourists to a specific area, and thus its success. It aims to look for the tourist's motives, needs and desires, then reach to the legitimate services that he wants, as well as the prices that suit his requirements, also to determine the appropriate payment methods and the required financial services and facilities, as well as covering all the amenities, fun and accommodation needed to meet the needs of tourists and finally leaving strong impressions and high psychological impact on their souls [9]. So, we can summarize its advantages as follows

* Develop the positive behaviour of tourists towards tourism service or product.

* Able to present the tourism destinations as new and exciting worlds.

* Effective on the smart professional presentation of tourism services.

* It is considered a catalyst for the tourism industry and as an effective indicator to measure tourism growth rates.

* Enhancing the expectations of prospected tourists.

* Presenting the expected and not tangible services to tourist on tourism places.

* Effective on establishing positive mental images of the tourism service or product and portraying a distinctive identity.

* Providing visual attractions that can attract and convince the tourist.

* The expressive ability of tourism entities before making the tourism decision, which is considered as catalyst for the decision.

* Clarifying the tourism information needed by the tourist.

* Clarifying the image of the tourism destination as one of the important tourism alternatives.

\section{The Identity}

It represents the group of similar social, psychological, living, and historical characteristics and advantages that express a universe in which a harmonious and similar group is reflected 
in the influence of these characteristics [10]. Also [11] defined it as a unique set of specifications that the organization's strategy or tourism body aspires to apply, which includes the promises made by the hotel establishment with its users and clients as it helps to create a strong emotional and functional positive relationship. The core of identity is on the urgent need of societies to assert themselves and disseminate their culture, as It reflects the citizenship requirements and belonging and highlighting the mould of culture and the essence of the values, civilization, humanity and history of societies.

\section{Identity Structure}

Davied Aaker's study of identity structure refers to it being divided into a core identity and an external identity that together organize identity elements to present the essence of an institutional entity

Core Identity: It represents the essence of the immortal hotel establishment. It has a central role that reflects the success of the hotel, its beliefs, values and philosophy are more connected to the institutional entity itself.

Extended Identity: It has the complementary elements of the hotel including details that help to understand the image of the hotel and its ability to be deeply memorized and relate to the user's life and its relationship with the hotel establishment [11].

\section{Visual Identity}

Visual identity is the visual approach resulting from the combination of marketing strategies, organizational structures, cultures, and elements of visual communication that exist for an entity [19]. Thus, it forms the visible face of the institution entity and the knowledge of the company, this visual identity should be compatible with the nature of the institution to support its presence and continuity to receiver, as Visual identity is one of the most important communication methods and a trust point between customers and tourism institutions. Also, it plays a key role in identifying the tourism establishment and making the product and tourism services immutable in memory [12].

\section{Visual Identity Role on the Promotion of Coastal Hotels}

The visual identity is one of the most important elements in the development of the coastal tourism sector because the hotels and coastal resorts are characterized by a special character that can be used in the textile design of the furniture and accessories to leave a distinctive influence representing the visual mental image of the hotel and gaining special qualities that increase guest opportunities to enjoy those qualities, The coastal tourism is rich with many components and marine elements that can be used on enriching the aesthetics identity of the hotel institution. Therefore, the benefit of the graphic treatments for these elements and using them marketing the identity of coastal hotels enriches the mental state of tourists and leaves positive impressions. According to the effective ability of tourism advertising to use the distinctive visual identities, the integration between ad- vertising sector and textile sector generates applicable tourism services with a meaningful and impact on tourism, Therefore, the synchronization resulting from the broadcast of tourism campaigns that are characterized by visual identity at the same time of using of graphic treatments inspired from on the hotel's furnishings and accessories in order to emphasize this identity and reflect a high level of relatively and credibility to the standard of living for tourists on hotels and resorts as that deepen its visual identity on tourists minds and increase credibility of tourism advertising. As long as the relationship between tourism market share and hotel market share is a positive one, as the increase of one means the increase of the other, so here the effectiveness of graphics treatments is crystal clear for tourism advertising as one of the promotional elements for hotels and coastal organizations that contribute strongly on increasing national tourism income. The advantages of visual identity on coastal hotels promotion are as follows

* Create a mental image conducive to the hotel's coastal features.

* Preparing tourist psychologically and creating distinctive service conditions.

* Increasing the rates of tourism investment.

* Increasing the rates of tourist's reservations on coastal hotels.

* Creating impressions, opinions and trends for the expected tourists.

* Encourage the positive tourism behaviour towards the coastal hotels.

* Increasing the future demand rates on hotels.

* Increasing the expected foreign currency rates to the country.

* Persuasive attraction elements for purchase hotel service.

* Reduce the fluctuations on tourism.

* Paying attention to enhancing tourists' loyalty according to credibility.

* Ability to change tourists desires and needs by focusing on the advantages of coastal cities.

\section{Increasing the Productivity of Hotels and Resorts}

The designer seeks to build a visual identity through the realization of the positive mental image of the hotel, trying to send effective messages about the coastal hotel entities and prepare the tourist mind for the enjoyable adventure that will take place during his visit. The research is based on constructing this identity through the embodiment of the different concepts of the coastal identity on the whole hotel entity or tourist resort to create a mental state of mind to which the tourist is psychologically, 
visually and mentally is influenced and also as an introduction to the characteristics of tourism in the coastal areas.

\section{Mental Image}

The mental image is one of the main motivations for the organization impressions, which is highlighted on its role in shaping a positive trend towards the tourism establishment which also helps to create some kind of preference for that organization, so the importance of paying attention to the mental images of coastal hotels is clear on stimulating the tourists behaviour's towards it also plays a prominent role in determining how the person is aware of the information sent to him and thus form his behaviour and determine the ceiling of his expectations and how to respond to the tourism organization. It has an effective ability to influence the tourist experiences and the expected tourism experiences in the future, which helps on preparing the tourist mentally and psychologically to his visit. Both Kotler and Claire defined it as a group of the ideas, beliefs, attitudes and feelings of an individual towards an organization or person [13]. A tourism advertisement can establish a good mental image of the tourism destination, as Image Advertising is an attempt to create a likable mental image of a product or company in the mind of the receptors that aims to link the advertised product or organization to a lifestyle or value. The mental image advertising aims to positively enhancing the image of the tourism destination and refers to its advantages and benefits, making it a distinct destination from its competitors, and makes it at the top of the tourism decision.

\section{Mental Image Components}

Cognitive component: It represents the main component of the mental image as it is connected to the cognitive side of the tourism destination or institution information. The mental image must be properly informed, reflecting the credibility of the tourism establishment, whether through advertising means or otherwise, in order not to allow the competitor to sabotage this image.

Effective component: It reflects the rate of psychological correlation as it is connected to the psychological and emotional dimensions of the tourist, also its component could be strengthened by focusing on building sympathy and high acceptance from tourists towards the tourism destination.

Behavioural component: This component is constructed by studying the behaviours toward tourism destination to be used as tourism attractions for the tourism destination also to enhance the positive impressions towards the tourism destination and reduce the negative points [14].

\section{Mental Image Characteristics}

* It is a dynamic, interactive and sophisticated process that goes through several successive stages and takes multiple forms.

* The mental image relates to the cognitive dimensions of individuals such as understanding, remembering, cognition and others.

* It is a relatively and variable process that may be affected by many factors that can change the rate of its stability.

* Affected by the circumstances and possibilities around it.

* It is also related to psychological dimensions where it has a strong relation with feelings and sense.

* The components of the mental image are integrated with each other in a societal context and influenced by the determinants of this society [15].

\section{Graphic Treatments}

It is the interactive relation that combines between the formulation and the content is in the form of an integrated visual message which makes it capable of communication, stimulation and impression creation through developing a symbolic system by choosing mixture of design elements such as shapes, colours, lighting, movement and the method of presenting these elements, in a way that could reveal the components and moving imagination to Perceptions. Designer uses the attractive forms to visually attract the tourist then harmonize with it from the perspective of knowledge and sense as form is used to attract and raise the attention of the recipient and generate the desire to interpret it according to indications of his previous experience, personal choice and reason [16] Graphic treatments offer a myriad of attractive visual features to provide an enormous number of visual stimuli for the visitor, who in turn translates these visual stimuli, extracting information, and thus being physically and mentally influenced. There are Multiple Graphic Treatments as Follows

\section{Abstraction}

It is based on the extraction of the basic graphic forms and re-presenting it on new form which generate rich graphic values resulting from simplifying shapes and generalization. Thus, it represents creativity and getting away from the stereotypical and organic forms of shapes and moving to its abstract entity and essence.

\section{Repetition}

Here the designer is seeking repetition of units and formal elements to create a visual rhythm and a pattern that creates a link between the design units. As the existence of a fixed optical pattern creates a kind of visual affinity that leads to a repetitive system that acts involuntarily to emphasize objects visually processed in design and creates unity and inter connectivity between its elements.

\section{Reduction}

It is one of the types of visual graphic treatments through which the designer is using forms symbolic dimensions either by reducing the visual relations of the shape or colour relations. 


\section{Complex components}

It depends on the optical components to form complex and overlapping formations that accordingly will create numerous optical relationships, generating impressive aesthetic values. It is characterized by complexity because of the overlapping lines and intersections of colours and curves, but it still provides many alternative forms to the same optical units.

\section{Childish Trend}

It depends on innate and initial formulation of the elements to be addressed in a simple and clear away from technical considerations complex.

\section{Relative Exaggeration}

It depends on the focus on a certain part of the form or design and exaggeration in size to capture attention according to the difference with real picture.

\section{Shape Analysis}

This treatment depends on reaching the basic and geometric elements which is the basic of the design on its structure and the base on the construction of the visual shape.

\section{Textile Furnishings and Paintings}

Textile furnishings and paintings represent one of the most important factors in the success of the visual identity of hotels and resorts. As it presents the creation of graphic treatments for civilization, natural and environmental history of the coastal landscape in the design of furniture and textile paintings, which in turn provide designer with the largest number of units and elements in weaving art that reflect the place and its originality and which combine the cultural heritage of each region. All this helps on enriching the tourism places and attract tourist to the spirit of coastal places and its beauty. Also, we can see that the furnishings of the hotel are one of the most important advantages on the internal impression of tourist about the quality of hotel. As this material is the tourist comforting factors and which integrates with hotel other services to determine the failure or success of the visit? As tourist spent a great time from his visit on hotel so this time should be comforted and psychological effective. The textile method which is used in the production of textile paintings (tapestry) it is textile style with a non-extended texture. It is called paintings or clams because the designs have contiguous colour spaces and each colour space is woven by its own weft as this weft is going through the spaces on the design thus in any two adjacent parts the weft is not crossing with the filaments of the near part except in special circumstances. As a result, the vertical incisions may extend to large spaces, and this depends on the accuracy of the weavers, and may appear in slanted areas, which is the most applied methods used to produce textile paintings.

It is known textile products that add the purity of taste and beauty of life to the best as well as its necessity for man as a necessary utilitarian commodity [17] that this applied method was previously used in the Pharaonic era and it is an advanced technique for the method of founded on decoration style used in the belts and pharaonic straps of King Amenhotep II. Textile paintings are one of the most important. It is used in The Production of Textile Paintings Several Ways Like

\section{a. Drawing on woven and printing}

b. Embroidery which starting after finishing the fabric by adding threads with needle to make the decoration.

c. The decoration is woven during the process of weaving in the normal manner, which embraces the threading and weaving threads with different fabric compositions [17].

The paintings or clams have been used in various ages to decorate the walls in different places, with its different taste such abstract artistic and descriptive and historical and heritage (pharaonic, Coptic, Islamic, popular, modern art). We can see that the textile paintings are of a distinctive character and high artistic value for their design of art, elements and its aesthetic value artistic units. As the aesthetic value is due to the decorations on them and because it is a cultural heritage that we cannot find an alternative now and because they record decorative elements and cultural legacies. It is one of the most important means to revive the different heritage of the arts in addition to the high value of their production by hand [18]. The artist who creates the textile paintings may formulate a topic about place or about a certain area that shows a specific story or to express the region and its history or events that passed through it and its people and rooting history. For example, a fishing trip can be recorded in a certain area or an archaeological element is observed in another area. Also, all tourism areas and monuments in each region can be recorded separately in several designs and to be implemented in the form of textile paintings [18]. Thus, the utilization of the natural characteristics of coastal cities depending on the graphic treatments of tourism advertisements reflects the nature of the coastal environment. It also adds many aesthetic sides to the textile objects, thus increasing the chances of localization of the heritage and the simulation of the tourist by conveying information through the textile commentator. It is also possible to start an exhibition with these textile paintings touring different countries to identify the tourist with different tourism area and what distinguishes it, and this works to attract the tourist and it is the final goal behind it.

The research provides one of the means that helps the designer to formulate the textile clams inspired from the outstanding spirit of the urban and natural environment of the coastal cities and recording tourism areas in several designs. It is implemented in the way of textile paintings to become a high quality and effective painting in its impact depending on the rich artistic value. As well as the reliance on the tourism advertising graphic treatments in the design of textile furnishings for coastal hotels such as chairs, pillows, carpets and other furnishings in parallel with the implementation of tourism advertising campaign based on the design of tourism posters and using them in various 
advertising channels to emphasize the visual identity of coastal hotels and attract the tourist by influencing his Mental and psychological state with the heritage and tourism of the coastal city starting from the place of accommodation in coastal hotel through its furnishings and textile articles. Therefore, We Formally State and Test in Our Study

H1: The use of graphic treatments for tourism advertising in the textile furnishings of hotels in coastal cities enriches their visual identity.

H2: The synchronized presentation of this tourism advertising with those textile furnishings has played an active role in confirming the identity of the coastal hotels.

\section{Study}

In this Study, we tested these ideas using a set of graphic treatments for tourism advertisements in furnishings and textile accessories for coastal hotels. We predicted that the use of graphic treatments for tourism advertising in the textile furnishings of hotels in coastal cities enriches their visual identity (H1). Also, the synchronization of these advertisements and furnishings will richness of the tourist hotel's visual identity and tourists' minds.

\section{Methods}

\section{Design, Participants and Procedure}

This study is followed by an experimental study of the use of a set of graphic treatments for tourism advertisements in furnishings and textile accessories for coastal hotels to study their impact on the visual identity of these hotels. In addition, the study of the synchronization's impact of these advertisements and furnishings on the richness of the tourist hotel's visual identity and tourists' minds (Figure 1-4).

\section{Recruitment of the Participants and Sample Size}

150 foreign tourists (men and women randomly selected, average age 41.5) in order to participate in this study. They were guests in the Egyptian Four-Season Hotel in Sharm-el sheikh during their checkout [20]. Participants in this study received three-frame printouts (for four designs), after instructions and Participants approval; the first frame includes graphic treatments that employed in different types of textile furnishings, the second frame included the tourist advertising synchronized with these furnishings and deliberate on the same graphics treatments. While the third frame included a questionnaire that included covariates, demographics and 15 elements to answer in order to measure the ability of these designs to empower the visual identity of those hotels and their synchronization impact. The average amount of time participants spent was 8 minutes 51 seconds [21].

After reading the papers, the participants replied to all elements in the questionnaire with totally agree, agree, don't agree: "The designer draws design elements from the coastal environment and expresses them, The textile designs showed a distinctive visual identity that expresses the Egyptian coastal entity, The design provided interesting touristic worlds capable of attracting you, Furniture designs and pendants have helped you relax and enjoy the hotel, The hotel's furniture and pendants designs provided a positive image of the Egyptian coastal tourist attractions, The design has attracted your attention, You feel a distinctive design for the coastal hotel furniture and pendants, The design gave the hotel a distinctive character distinguished from its competitors, The information contained in the advertisement was simple and easy to read and understand, The design was able to capture a distinctive visual image of the hotel, The design was characterized by aesthetic elements enriched by the institutional identity of the hotel, The reliance on the formal elements in both the tourist advertisement, the hotel interior prints and the interior textile hotel designs works to prove the mental image of the coastal hotel, The synchronization of the tourist advertising with the hotel's textile designs based on the same graphic treatment emphasizes the hotel's visual identity and enriches it, The consolidation of the formal elements of the hotel, both in its interior textile designs and its promotional announcements, increases the credibility of the hotel service, The ad was able to establish a mental image of the tourist destination meritoriously. Each model was evaluated in a (Table 1-5) and then treated statistically. 16 questionnaires were excluded for their incomplete answers and 134 samples were left valid for analysis as shown in Table 1 .

Table 1: Response Rate.

\begin{tabular}{|c|c|c|c|c|}
\hline Ser. & $\begin{array}{c}\text { The Distributed } \\
\text { Questionnaires }\end{array}$ & $\begin{array}{c}\text { The Returned } \\
\text { Questionnaires }\end{array}$ & $\begin{array}{c}\text { The Excluded } \\
\text { Questionnaires }\end{array}$ & The Questionnaires Related to Analysis \\
\hline Number & 150 & 150 & 16 & 134 \\
\hline Percentage & $100 \%$ & $100 \%$ & $10.60 \%$ & $\% 89.33$ Total Distributed Questionnaires \\
\hline
\end{tabular}

Table 2: The results of the Questionnaire for the Design (1), Figure 1, and the Percentage weight for each element of the Questionnaire was calculated according to the responses of the Participants to the Phrase to show us the Relative Weight of each Statement, and these words are arranged according to the Percentage weight where the statement 1 in the First statement in the Order and so on.

\begin{tabular}{|c|c|c|c|c|c|c|c|c|}
\hline \multirow{3}{*}{ Order } & \multirow{3}{*}{$\begin{array}{l}\text { Percentage } \\
\text { Weight }\end{array}$} & \multicolumn{6}{|c|}{ Degree of Response } & \multirow{3}{*}{ No. of Items } \\
\hline & & \multicolumn{2}{|c|}{ Not Agree } & \multicolumn{2}{|c|}{ Agree } & \multicolumn{2}{|c|}{ Strongly Agree } & \\
\hline & & $\%$ & Frequency & $\%$ & Frequency & $\%$ & Frequency & \\
\hline 6 & 2.72 & 2.99 & 4 & 21.64 & 29 & 75.37 & 101 & 1 \\
\hline
\end{tabular}




\section{Current Trends in Fashion Technology \& Textile Engineering}

\begin{tabular}{|c|c|c|c|c|c|c|c|c|}
\hline 2 & 2.8 & 2.73 & 5 & 12.69 & 17 & 83.58 & 112 & 2 \\
\hline 8 & 2.67 & 8.96 & 12 & 14.92 & 20 & 76.12 & 102 & 3 \\
\hline 11 & 2.6 & 11.94 & 16 & 16.42 & 22 & 71.64 & 96 & 4 \\
\hline 1 & 2.87 & 8.21 & 11 & 13.43 & 18 & 78.36 & 105 & 5 \\
\hline 10 & 2.63 & 10.45 & 14 & 15.67 & 21 & 73.88 & 99 & 6 \\
\hline 5 & 2.75 & 8.96 & 12 & 7.46 & 10 & 83.58 & 112 & 7 \\
\hline 7 & 2.69 & 8.21 & 11 & 14.18 & 19 & 77.61 & 104 & 8 \\
\hline 6 Repeated & 2.72 & 7.46 & 10 & 12.69 & 17 & 79.85 & 107 & 9 \\
\hline 9 & 2.66 & 7.46 & 10 & 18.66 & 25 & 73.88 & 99 & 10 \\
\hline 4 & 2.76 & 7.46 & 10 & 8.96 & 12 & 83.58 & 112 & 11 \\
\hline 9 Repeated & 2.66 & 8.21 & 11 & 17.16 & 23 & 74.63 & 100 & 12 \\
\hline 2 Repeated & 2.8 & 5.97 & 8 & 8.21 & 11 & 85.82 & 115 & 13 \\
\hline 3 & 2.78 & 3.73 & 5 & 14.93 & 20 & 81.34 & 109 & 14 \\
\hline 5 Repeated & 2.75 & 5.22 & 7 & 14.18 & 19 & 80.6 & 108 & 15 \\
\hline
\end{tabular}

Table 3: The results of the Questionnaire for the Design (2), Figure 2, and the Percentage weight for each element of the Questionnaire was calculated according to the responses of the Participants to the expression to Show the Relative weight of each Statement. These words are arranged according to the Percentage weight, where the Statement 1 in the first Statement in the order and so on.

\begin{tabular}{|c|c|c|c|c|c|c|c|c|}
\hline \multirow{3}{*}{ Order } & \multirow{3}{*}{$\begin{array}{l}\text { Percentage } \\
\text { Weight }\end{array}$} & \multicolumn{6}{|c|}{ Degree of Response } & \multirow{3}{*}{ No. of Items } \\
\hline & & \multicolumn{2}{|c|}{ Not Agree } & \multicolumn{2}{|c|}{ Agree } & \multicolumn{2}{|c|}{ Strongly Agree } & \\
\hline & & $\%$ & Frequency & $\%$ & Frequency & $\%$ & Frequency & \\
\hline 1 & 2.86 & 4.48 & 6 & 5.22 & 7 & 90.3 & 121 & 1 \\
\hline 8 & 2.76 & 9.7 & 13 & 4.48 & 6 & 85.82 & 115 & 2 \\
\hline 2 & 2.84 & 1.49 & 2 & 12.69 & 17 & 85.82 & 115 & 3 \\
\hline 4 & 2.81 & 6.72 & 9 & 5.97 & 8 & 87.31 & 117 & 4 \\
\hline 7 & 2.77 & 4.48 & 6 & 14.18 & 19 & 81.34 & 109 & 5 \\
\hline 10 & 2.68 & 8.96 & 12 & 14.18 & 19 & 76.87 & 103 & 6 \\
\hline 6 & 2.78 & 3.73 & 5 & 14.93 & 20 & 81.34 & 109 & 7 \\
\hline 3 & 2.83 & 3.73 & 5 & 9.7 & 13 & 86.57 & 116 & 8 \\
\hline 6 Repeated & 2.78 & 8.21 & 11 & 5.97 & 8 & 85.82 & 115 & 9 \\
\hline 4 Repeated & 2.81 & 6.72 & 9 & 5.97 & 8 & 87.31 & 117 & 10 \\
\hline 2 Repeated & 2.84 & 5.97 & 8 & 3.73 & 5 & 90.3 & 121 & 11 \\
\hline 11 & 2.66 & 10.45 & 14 & 12.69 & 17 & 76.87 & 103 & 12 \\
\hline 9 & 2.71 & 8.21 & 11 & 12.69 & 17 & 79.1 & 106 & 13 \\
\hline 6 Repeated & 2.78 & 4.48 & 6 & 12.69 & 17 & 82.84 & 111 & 14 \\
\hline 5 & 2.8 & 5.97 & 8 & 8.21 & 11 & 85.82 & 115 & 15 \\
\hline
\end{tabular}

Table 4: The Results of the Questionnaire for the Design (3), Figure 3, and the Percentage weight for each Element of the Questionnaire were calculated according to the responses of the Participants to the expression to show the Relative weight of each statement. These statements are arranged according to the Percentage weight, where the Statement 1 in the First Statement in the Order and so on.

\begin{tabular}{|c|c|c|c|c|c|c|c|c|}
\hline \multirow{3}{*}{ Order } & \multirow{3}{*}{$\begin{array}{l}\text { Percentage } \\
\text { Weight }\end{array}$} & \multicolumn{6}{|c|}{ Degree of Response } & \multirow{3}{*}{ No. Of Items } \\
\hline & & \multicolumn{2}{|c|}{ Not Agree } & \multicolumn{2}{|c|}{ Agree } & \multicolumn{2}{|c|}{ Strongly Agree } & \\
\hline & & $\%$ & Frequency & $\%$ & Frequency & $\%$ & Frequency & \\
\hline 8 & 2.69 & 10.45 & 14 & 10.45 & 14 & 79.1 & 106 & 1 \\
\hline 11 & 2.6 & 5.97 & 8 & 27.61 & 37 & 66.42 & 89 & 2 \\
\hline 10 & 2.63 & 7.46 & 10 & 21.64 & 29 & 70.9 & 95 & 3 \\
\hline 9 & 2.64 & 11.94 & 16 & 11.94 & 16 & 76.12 & 102 & 4 \\
\hline 8 Repeated & 2.69 & 8.21 & 11 & 14.92 & 20 & 76.87 & 103 & 5 \\
\hline 7 & 2.71 & 4.48 & 6 & 20.15 & 27 & 75.37 & 101 & 6 \\
\hline
\end{tabular}




\section{Current Trends in Fashion Technology \& Textile Engineering}

\begin{tabular}{|c|c|c|c|c|c|c|c|c|}
\hline 11 Repeated & 2.6 & 11.94 & 16 & 16.42 & 22 & 71.64 & 96 & 7 \\
\hline 8 Repeated & 2.69 & 8.21 & 11 & 14.93 & 20 & 76.87 & 103 & 8 \\
\hline 1 & 2.87 & 0 & 0 & 12.69 & 17 & 87.31 & 117 & 9 \\
\hline 8 Repeated & 2.69 & 5.97 & 8 & 18.66 & 25 & 75.37 & 101 & 10 \\
\hline 5 & 2.78 & 6.72 & 9 & 8.21 & 11 & 85.07 & 114 & 11 \\
\hline 3 & 2.84 & 1.49 & 2 & 14.93 & 20 & 83.58 & 112 & 12 \\
\hline 2 & 2.86 & 2.24 & 3 & 9.7 & 13 & 88.06 & 118 & 13 \\
\hline 4 & 2.83 & 6.72 & 9 & 3.73 & 5 & 89.55 & 120 & 14 \\
\hline 6 & 2.72 & 8.21 & 11 & 11.19 & 15 & 80.6 & 108 & 15 \\
\hline
\end{tabular}

Table 5: The Results of the Questionnaire for the Design (4), Figure 4, The Percentage Weight for each element of the Questionnaire was calculated according to the responses of the Participants to the expression to indicate the Relative weight of each statement. These terms are arranged according to the Percentage weight, where the Statement 1 in the First statement in the order and so on.

\begin{tabular}{|c|c|c|c|c|c|c|c|c|}
\hline \multirow{3}{*}{ Order } & \multirow{3}{*}{$\begin{array}{l}\text { Percentage } \\
\text { Weight }\end{array}$} & \multicolumn{6}{|c|}{ Degree of Response } & \multirow{3}{*}{ No. Of Items } \\
\hline & & \multicolumn{2}{|c|}{ Not Agree } & \multicolumn{2}{|c|}{ Agree } & \multicolumn{2}{|c|}{ Strongly Agree } & \\
\hline & & $\%$ & Frequency & $\%$ & Frequency & $\%$ & Frequency & \\
\hline 10 & 2.62 & 9.7 & 13 & 18.66 & 25 & 71.64 & 96 & 1 \\
\hline 5 & 2.7 & 7.46 & 10 & 14.93 & 20 & 77.61 & 104 & 2 \\
\hline 6 & 2.69 & 4.48 & 6 & 21.64 & 29 & 73.88 & 99 & 3 \\
\hline 4 & 2.71 & 8.21 & 11 & 12.69 & 17 & 79.1 & 106 & 4 \\
\hline 1 & 2.81 & 2.24 & 3 & 14.93 & 20 & 82.84 & 111 & 5 \\
\hline 6 repeated & 2.69 & 9.7 & 13 & 11.19 & 15 & 79.1 & 106 & 6 \\
\hline 11 & 2.6 & 15.67 & 21 & 8.21 & 11 & 76.12 & 102 & 7 \\
\hline 6 & 2.69 & 5.22 & 7 & 20.15 & 27 & 74.63 & 100 & 8 \\
\hline 9 & 2.63 & 10.45 & 14 & 15.67 & 21 & 73.88 & 99 & 9 \\
\hline 7 & 2.68 & 5.97 & 8 & 20.15 & 27 & 73.88 & 99 & 10 \\
\hline 8 & 2.66 & 5.97 & 8 & 21.64 & 29 & 72.39 & 97 & 11 \\
\hline 2 & 2.8 & 6.72 & 9 & 13.43 & 18 & 79.85 & 107 & 12 \\
\hline 3 & 2.75 & 0 & 0 & 25.37 & 34 & 74.63 & 100 & 13 \\
\hline 1 repeated & 2.81 & 1.49 & 2 & 15.67 & 21 & 82.84 & 111 & 14 \\
\hline 3 repeated & 2.75 & 4.48 & 6 & 16.42 & 22 & 79.1 & 106 & 15 \\
\hline
\end{tabular}

\section{Stimulus Materials}

Several graphic treatments for tourism advertisements inspired by the coastal environment, which rely on coloured fish, coral reefs, marine jellyfish and other sea components, have been designed in different forms of visual treatments, either by using combination compositions, overlapping formations, reduction or using the childish trend or others in treatment to produce visual elements that are attractive and dazzling.

These geographical designs are used on pillows, carpets, billboards, chairs and curtains inside coastal hotels, on a way that highlighting the distinctive visual identity of the coastal cities. Taking into consideration the textile method used, the number of thread and its kind, the number of the weft and its type in addition to the number of wefts and filaments. Preparing tourism advertising inspired from the same visual graphical treatments to present for the Participants at the same time to assert the identity and image of the coastal hotel which can be used on hotels entrance boards, on ways to hotel or on different advertising channels, also inside hotel printouts.

\section{Analysis and Results}

The questionnaires were received from the participants and thanked them, then the results of the questionnaires for the four designs were analysed statistically, as shown in the following tables for each design:

Table 2 shows the Participants responses for the questionnaire of Figure 1. The Result from 1 to 10 indicates that the strong approval rate for the participants ranged between 83.58 and $71.64 \%$. This confirms the initial hypothesis of the research which states that the use of graphic treatments for tourist advertisements in the textile furnishings of the hotels of the coastal cities enriches their visual identity. The participants' responses to the statements 11 to 15 of the study of the synchronization of the presentation of tourism advertisements and the design of the textile furnishings of the coastal hotels indicate that the 


\section{Current Trends in Fashion Technology \& Textile Engineering}

strong approval rate ranged between (85.82 and 74.63\%). This confirms the second hypothesis of the research, stated that the synchronized presentation of this tourism advertising with those textile furnishings has played an active role in confirming the identity of the coastal hotels Figure 1. achieved the strongest approval of the participants for its ability to embody distinctive and expressive visual identity of the Egyptian coastal entity be- tween the four designs subject to the questionnaire. The design was distinguished by distinctive visual elements derived from Egyptian coastal entity and were visually employed with distinctive design determinants, angles and design directions that highlighted the identity and the specific optical character of the coastal hotel. And Figure 1 achieved strong consensus from the participants in general in the elements of the 15 questionnaires.

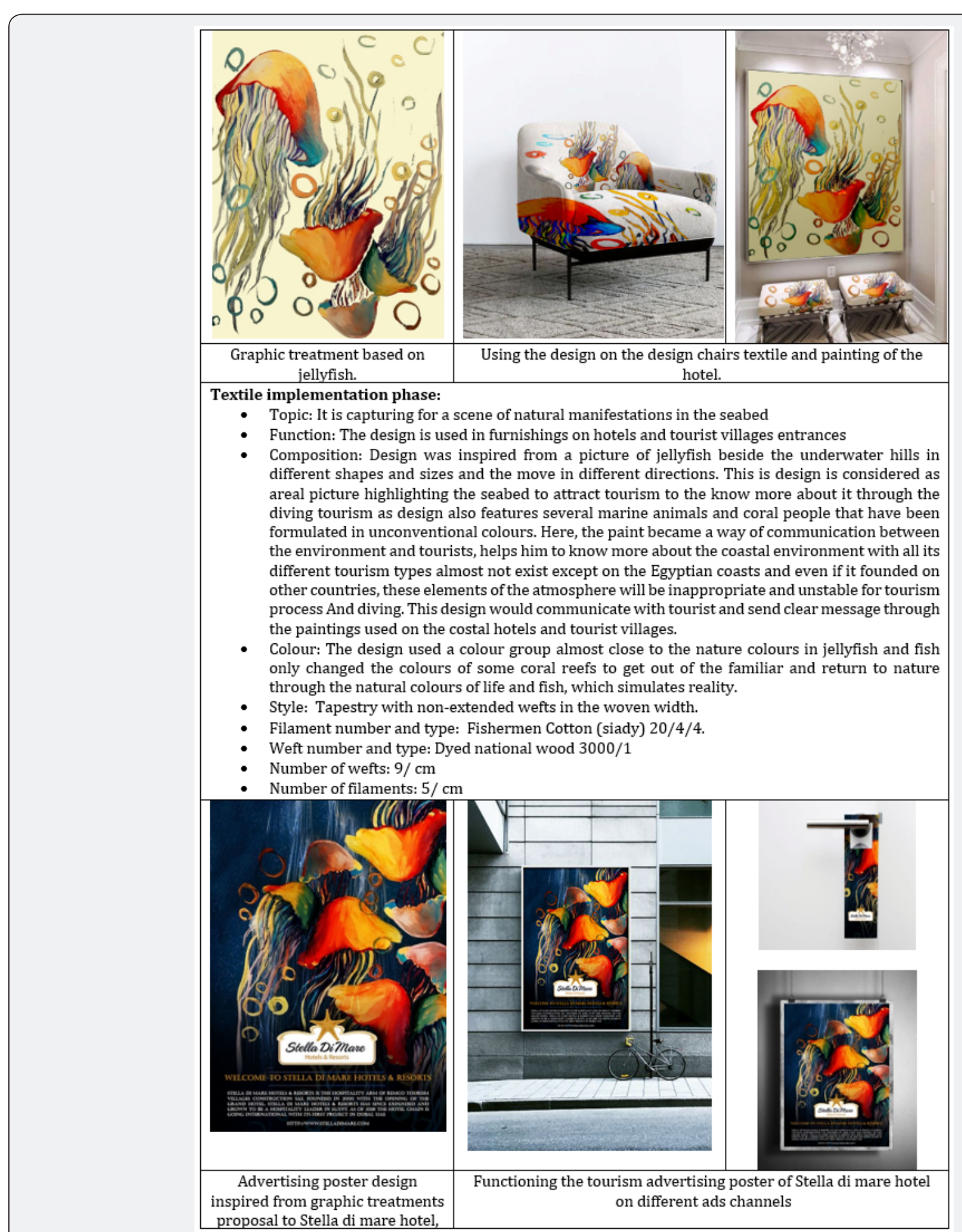

Figure 1: For the Design of Paintings, Furnishings and Chairs for a Coastal Hotel Inspired from the Shape of Jellyfish and the Advertising Poster Design Inspired from Graphic Treatments Proposal to Stella Di Mare Hotel. 


\section{Current Trends in Fashion Technology \& Textile Engineering}

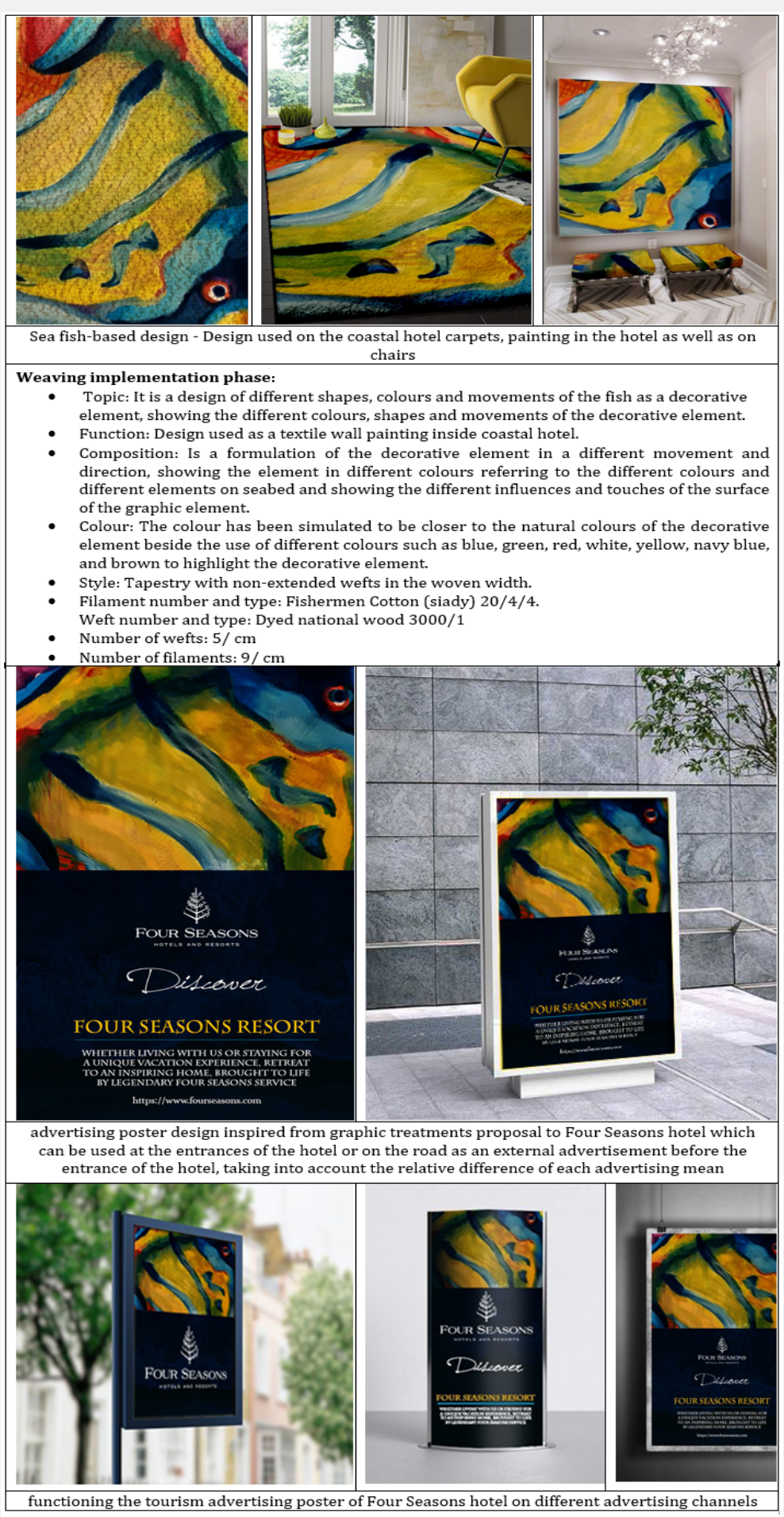

Figure 2: For the Design of Paintings, Carpets, Furniture and Chairs Fabric for a Coastal Hotel Inspired by Fish and Advertising Poster Design Inspired from Graphic Treatments Proposal to Four Seasons Hotel.

Table 3 shows the Participants responses for the questionnaire of Figure 2. The Result from 1 to 10 indicates that the strong approval of the participants ranged from 76.87 to 90.30 $\%$. This confirms the initial hypothesis of the research that the use of graphic treatments for tourism advertisements in the textile furnishings of the hotels of the coastal cities enriches their visual identity. The participant's responses to the statements 11 to 15 of the study of the synchronization of the presentation of tourism advertising and the design of the textile furnishings of the coastal hotels indicate that the strong approval rate ranged between 90.30 and $76.87 \%$. This confirms the second hypothesis of the research, stated that the synchronized presentation of this tourism advertising with those textile furnishings has played an active role in confirming the identity of the coastal hotels Figure 2. achieved the strongest approval for the participants among the four designs presented in questionnaire to embody the de- 


\section{Current Trends in Fashion Technology \& Textile Engineering}

sign elements for coastal environment. The design was based on a sector of the shape of a fish and was clearly employed in various textile designs and pendants, in addition to the clarity of this sector in the tourist declaration, The participants selected the highest strong approval for this design among the four designs presented in his embodiment of the exciting worlds, in addition to his ability to impress participants effectively according to the design in bright and bright colours, as well as the design record
[23]. In its ability to demonstrate a distinctive entity for the design of distinctive hotel suites. The participants agreed strongly on the design of the four designs attached to the ability of the design to reflect the distinctive visual image of the hotel because of the elements of aesthetic and attractive and influential. The tourist declaration of this design achieved the highest approval among the four designs in its effectiveness to establish a mental image of the Egyptian tourist destination with merit.

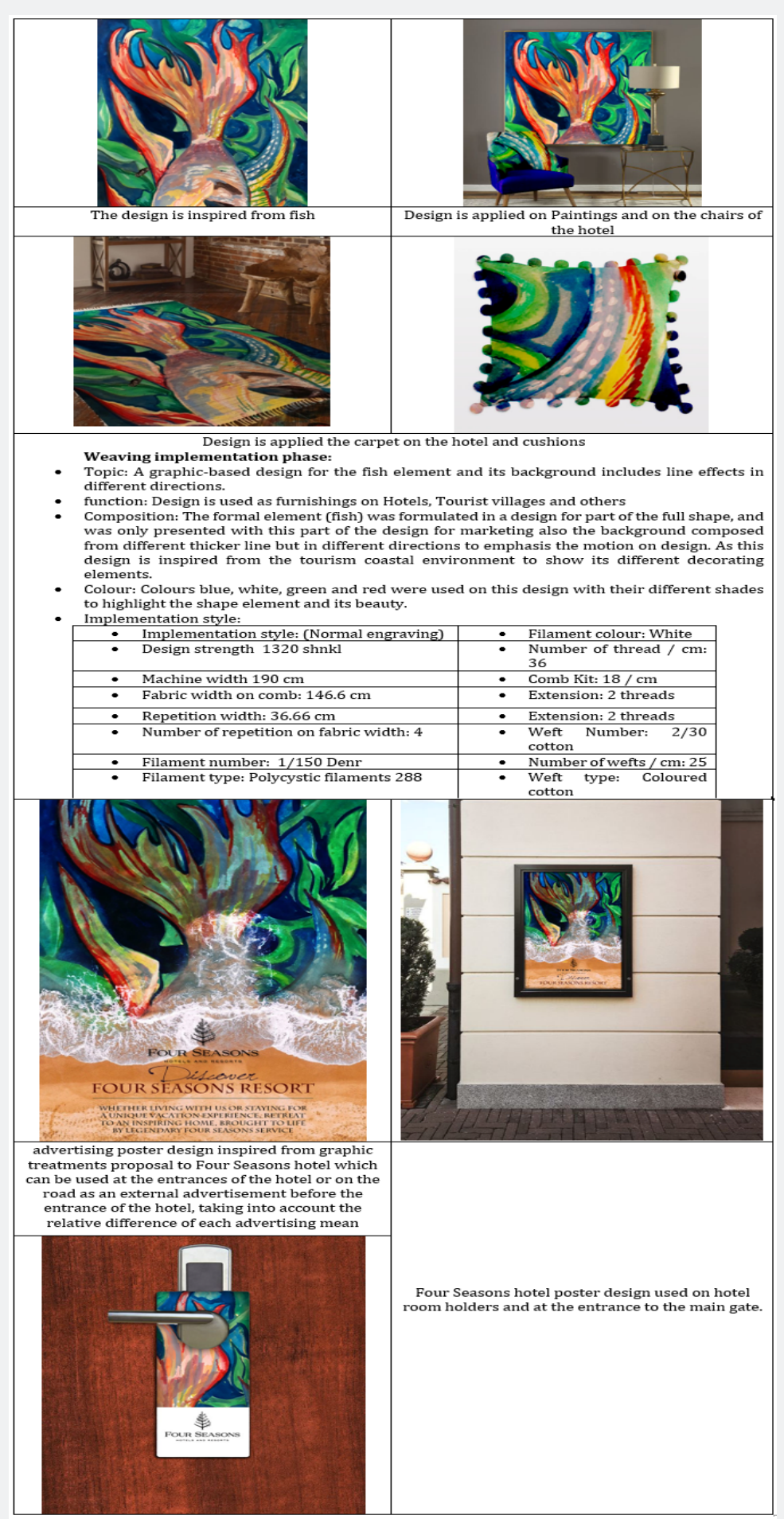

Figure 3: For the Design of Paintings, Carpets, Chairs Fabric and Cushions for a Coastal Hotel Based on Fishes and Advertising Poster Design Inspired from Graphic Treatments Proposal to Four Seasons Hotel. 


\section{Current Trends in Fashion Technology \& Textile Engineering}

Table 4 shows the Participants responses for the questionnaire of Figure 3. The Result from 1 to 10 indicates that the strong approval of the participants ranged from 87.31 to $70.90 \%$. This confirms the initial hypothesis of the research that the use of graphic treatments for tourism advertising in the textile furnishings of the hotels of the coastal cities enriches their visual identity. The participant's responses to the statements 11 to 15 of the study of the synchronization of the presentation of tourism advertisements and the design of the textile furnishings of the coastal hotels indicate that the strong approval rate ranged between 80.60 and $89.55 \%$. This confirms the second hypothesis of the research, stated that the synchronized presentation of this tourism advertising with those textile furnishings has played an active role in confirming the identity of the coastal hotels Fig- ure 3. achieved the strongest approval among the four designs in the ease of reading the information contained in the tourist declaration and understanding it according to the appearance of the writings clearly on the background as well as the use of lines clear and easy to read the participants. In addition, it has received the highest approval in the four design designs to highlight the hotel's visual identity resulting from the synchronizing of the tourist advertisement with the hotel's designs, which are based on fixed graphic treatments [24]. This highlights the effectiveness of employing the same graphic treatments in the interior of the hotel whether in its furniture, its internal advertising publications, as well as the external entity represented by its foreign tourist advertisements.

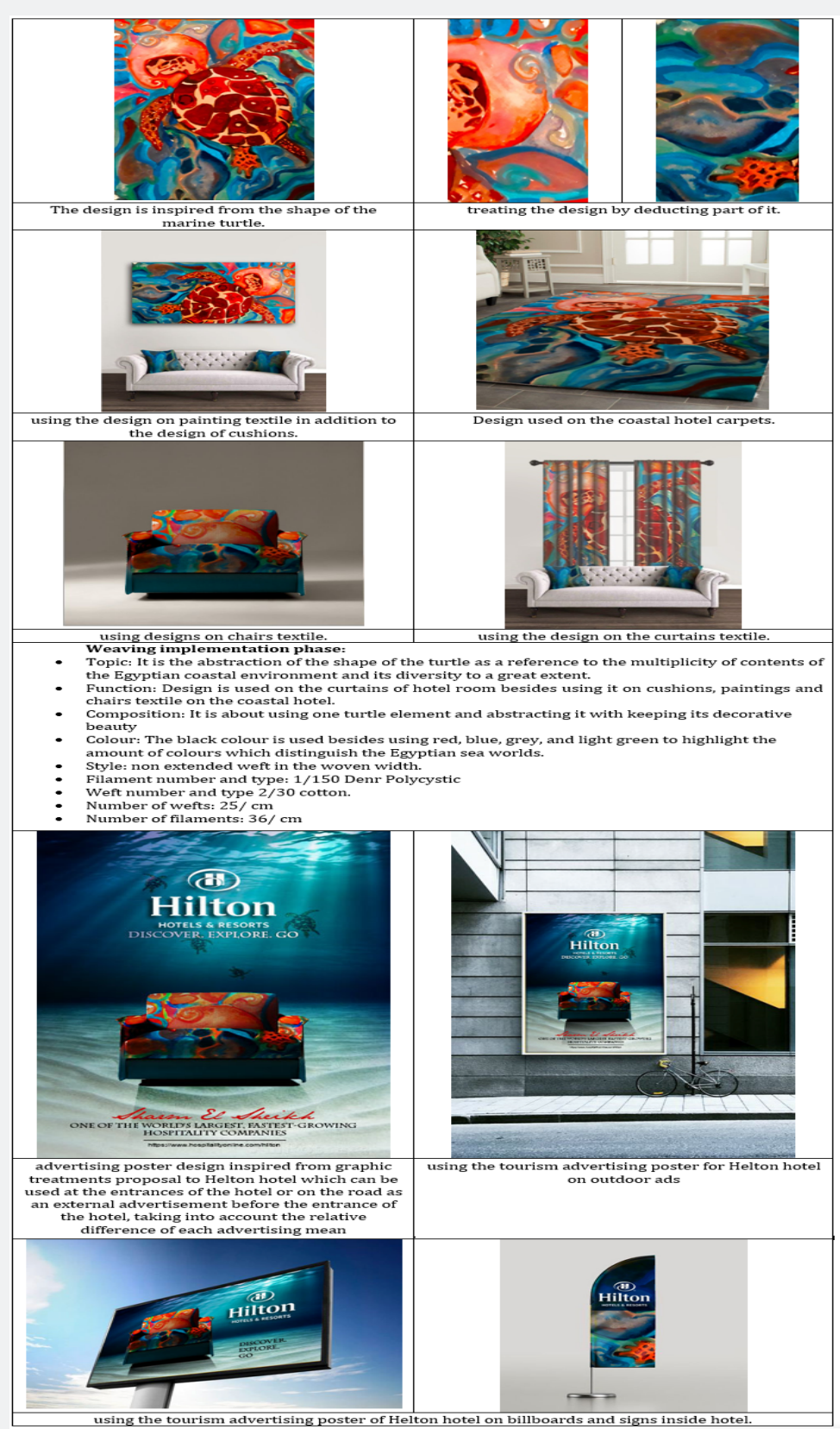

Figure 4: For the Design of Paintings, Carpets, Chairs Fabric and Cushions for a Coastal Hotel Based on Fishes and Advertising Poster Design Inspired from Graphic Treatments Proposal to Helton Hotel. 
It is clear to us that this synchronization reflected the credibility of the hotel service positively as it received the relatively strong approval of the four designs. Table 5 shows the Participants responses for the questionnaire of Figure 4. The Result from 1 to 10 indicates that strong approval of the participants ranged between 71.64 and $82.84 \%$. This confirms the initial hypothesis of the research that the use of graphic treatments for tourism advertisements in the textile furnishings of the hotels of the coastal cities enriches their visual identity. The participant's responses to the terms 11 to 15 of the study of the synchronization of the presentation of tourist advertisements and the design of the textile furnishings of the coastal hotels indicate that the strong approval rate ranged between 72.39 and $82.84 \%$. This confirms the second hypothesis of the research, stated that the synchronized presentation of this tourism advertising with those textile furnishings has played an active role in confirming the identity of the coastal hotels Figure 4. recorded the highest approval for the four designs attached to its ability to represent an effective positive image of the coastal Egyptian monuments. The design included a turtle and was treated geographically in an abstract manner and relatively contrasting colours were used. The design received the highest approval rating among the four designs in its ability to attract participants and draw their attention.

\section{Conclusion and Discussion}

The results of the study showed support for our prediction. The results indicated the positive evaluation of the participants in the effective use of graphic treatments for tourist advertising in the textile textiles of the hotels of the coastal cities in enriching their visual identity, as well as their positive evaluation of the presentation of their role to show the identity of the coastal hotel. In addition, statistical analysis revealed that the unified graphics in both the tourist advertising of the external entity of the hotel and the furnishings of the textile hotel comprising its internal entity have an effective role in linking the unit to the visual entity of the coastal hotel [25].

More specifically, the statistical results showed that the unification and linking of elements of graphic treatments in advertising and textile furnishings helped to form a distinctive identity, which stimulated the enjoyment of the tourist hotel, providing him with a distinct competitive advantage of his competitors depending on the visual and mental situation that needed the feelings of the participant during the experiment.

The results indicated that the integration of hotel elements, whether in its advertisements or textile designs, creates a specific visual image of the hotel, which constitutes the determinants and elements of its visual identity.

According to the data, the synchronization of the display of both these tourism advertisements and the textile furnishings with the standardization of the graphics used in them provides elements of support and the formation of the visual identity of the hotel distinct from competitors, and that the unification of visual elements in both advertising and textile mattresses of the coastal hotels increases the credibility of the hotel service where It shows the keenness of the hotel establishment to highlight the quality of hotel service, which is reflected positively on the image of the coastal hotel mental mind of the tourist(Appendix).

\section{Acknowledgements}

I would like to thank the Four Seasons Hotel administration stuff in Sharm El Sheikh for its great support for the experiment, also the participants for their enrichment comments in the experience examination.

\section{References}

1. Issa HA (2016) Tourism and Its Role in the Field of Economic and Social Development. Tanta University, Law Third Annual Conference on Law School,Egypt, pp 45-368.

2. Jönsson Cristina (2005) Tourism Marketing Basics. p1-36.

3. Salehi Hassan, M Farahbakhsh (2014) Tourism Advertisement Management and Effective Tools in Tourism Industry. International Journal of Geography and Geology, Iran, 3(10):124-134.

4. Benckendorff PJ (2001) Planning for the future: A Study of Australian Tourist Attractions. James Cook University, Australia, p1-14.

5. Sebastian V, M Felix (2009) Tourism Destination attractiveness: Attractions, Facilities, and people as predictors. Tourism Analysis, USA, 14 (1):621-636.

6. Kim J, L Lee (2002) Critical Design factors for successful e-commerce systems. Behaviour and Information Technology Journal, South Korea, 21(3): 185-199.

7. Abul Hasan MM (2015) promotional Activities in the strategic tourism. Development of Lapland, Finland, pp1-51.

8. Nada MA (2017) Evaluating the Mental Image of Egypt on Tourism Posters and its Effectiveness on Supporting Tourism, Journal of Architecture and Arts, Egypt, 8 (1):1-23.

9. Abdulkader MA (2013) Role of Advertising in Tourism Marketing. University Foundation for Studies Publishing and Distribution, Lebanon, Beirut.

10. Tutchener D (2013) Collective Identity and Heritage: Ebb and Flow at National and Global Levels. Journal of Globalization Studies 4 (2): 96103.

11. Lumene C (2014) Brand image and identity. p7-66

12. Hazal Bilgütay (2013) The Importance of Corporate Identity Design with Comparative Examples. Izmir University of Economics, Faculty of Fine Arts and Design, Turkey. p1-15.

13. Kotler P, K Lane (2012) Marketing management, Prentice Hall, New Jersey.

14. Kordy AE (2001) Managing the Mental image of Organizations within the Framework of Social responsibility: A field study on a sample of Egyptian pharmaceutical companies, Faculty of commerce, Business administration department, Benha University, Egypt.

15. Hagag MA (2007) Media Role on Forming the Mental Image of Upper Egypt to Egyptian Youth. Cairo University, Faculty of Mass Communication, Egypt, pp 45-339.

16. Abdel Hamid ES (2003) An Elemental Investigation through Composition Treatments in Television Advertising. Faculty of Applied Arts, Helwan University, Egypt. 
17. Kafafi M (2016) Technical and Formal Characteristics of Textile Characters in Some Villages of the Governorates of Egypt. Minia University, Faculty of Education, Egypt, pp 187-196.

18. Al-Sayyad GM (2018) Dialogue between lines, colours and textile compositions as an intro to the design of accessories and furnishings. Journal of Architecture and Arts 8 (1): 456-497.

19. Buendia D, N Meljoum (2006) The Importance of Managing the Corporate Identity. Lulea University of Technology, Master's thesis, Sweden, p1-69.

20. Asaad, et al. (2016) The technical characteristics of the textile industry in some villages of Egypt, Faculty of education, Elmenia University, Egypt.
21. Laforet, S (2008) Size, strategic, and market orientation effects on innovation. Journal of business Research, The University of Sheffield, Management School, UK 61(7): 753-764.

22. Taha AE (2011) Managing the Mental Image of Organizations within the Framework of Social Responsibility: A Field Study on A Sample of Egyptian Pharmaceutical Companies, Benha University, Faculty of Commerce, Egypt, pp1-9.

23. http://usc.edu.eg/uploads/9ea9756c606bae9fe0ae0fc046d4073d. pdf

24. http://www.albawabhnews.com/2416459

25. www.businessdictionary.com

\section{Your next submission with Juniper Publishers will reach you the below assets}

- Quality Editorial service

- Swift Peer Review

- Reprints availability

- E-prints Service

- Manuscript Podcast for convenient understanding

- Global attainment for your research

- Manuscript accessibility in different formats

( Pdf, E-pub, Full Text, Audio)

- Unceasing customer service

Track the below URL for one-step submission https://juniperpublishers.com/online-submission.php 